\title{
INTERNACIONALIZAÇÃO DO SETOR SUCROENERGÉTICO BRASILEIRO E SUAS CONSEQUÊNCIAS EM GOIÁS
}

\section{SECTOR SUGARCANE BRAZILIAN INTERNACIONALIZATION AND ITS CONSEQUENCES IN GOIAS}

\author{
José Paulo Pietrafesa \\ Professor Doutor do Programa de Pós-Graduação em Educação (PPGE-UFG) \\ jppietrafesa@gmail.com \\ Thiago Brito Steckelberg \\ Mestre em Ciências Ambientais pela UniEvangélica \\ thiagosteck@gmail.com \\ Pedro Araújo Pietrafesa \\ Professor Doutor do Curso de Relações Internacionais \\ e do Mestrado em Desenvolvimento e Planejamento Territorial. \\ pedro.pietrafesa@gmail.com
}

\begin{abstract}
Resumo
O objetivo desse artigo é analisar o cenário de internacionalização do setor sucroenergético brasileiro e suas consequências, principalmente no estado de Goiás. A primeira parte do trabalho consiste na contextualização das principais correntes do pensamento econômico a respeito da participação do capital externo na economia nacional. Em seguida, serão apresentados os conceitos e diferentes tipos de Investimento Direto Estrangeiro (IDE) e logo depois um breve histórico da participação do capital internacional na economia brasileira. A próxima seção do artigo aborda o investimento externo especificamente na agropecuária e no setor sucroenergético. Por fim, a última seção trata das consequências da internacionalização do setor em Goiás, com destaque para os impactos sociais e ambientais desse processo. Pretende-se, com este artigo, realizar contribuições no estudo da internacionalização sucroenergética, destacando suas consequências para a sociedade brasileira como um todo e para o estado de Goiás.
\end{abstract}

Palavras-chave: Capital internacional na economia brasileira. Investimento externo no setor sucroenergético. Novo contexto do setor sucroenergético no estado de Goiás.

\begin{abstract}
The aim of this paper is to analyze the scenario of internationalization of the Brazilian sugarcane industry and its consequences, especially in the state of Goiás. The first part of the work consists of the theoretical context of the mainstream of economic thought concerning the participation of foreign capital in the national economy. Then the concepts and different types of Foreign Direct Investment will be presented (IDE) and soon after a brief history of participation of international capital in the Brazilian economy. The next section of the article deals specifically foreign investment in agriculture and sugarcane industry. Finally, the last section deals with the sector internationalization and its consequences in Goiás, highlighting the social and environmental impacts of this process. The intention with this article is to make
\end{abstract}


contributions in the study of sugarcane internationalization, highlighting its impact on Brazilian society as a whole and for the state of Goiás.

Keywords: International capital in the Brazilian economy. Foreign investment in the sugar and energy sector. New context of the sugarcane industry in the state of Goias.

\section{Introdução}

Desde os tempos da colonização pelos portugueses, registrou-se a presença do capital estrangeiro na economia do Brasil. Já na primeira atividade econômica de relevância implementada no território brasileiro, os engenhos de açúcar, recursos provenientes da Holanda contribuíram com boa parte do financiamento desse setor econômico (FURTADO, 2008). Ao longo de todo o período colonial, seguindo pela independência até aos dias atuais, teve continuidade esse processo de entrada de investimentos externos no Brasil, com diferenciações de intensidade e alocação nos setores da economia conforme os períodos históricos. Na década de 1990, a tendência de internacionalização da economia brasileira atingiu patamares elevados, o que pode ser notado pelo volume cada vez maior de empresas multinacionais atuando em território nacional (SARTI; LAPLANE, 2002)

A partir do ano 2000, percebe-se o crescente interesse de investidores externos no setor sucroenergético, atraídos pelas promissoras expectativas do crescimento do setor por fatores de mercado, como a comercialização dos carros cujo motor funciona tanto à base do etanol como da gasolina, possibilitando assim a opção pelo consumidor conforme as vantagens do momento. Também pela necessidade de alternativas renováveis, menos poluentes, para gradual substituição dos derivados do petróleo (combustíveis fósseis). Todos estes fatores contribuíram para atrair o investimento estrangeiro para o setor sucroalcooleiro.

O objetivo deste artigo é identificar o processo de internacionalização do capital que passaram a controlar as usinas de produção de açúcar e etanol no Brasil, em geral, e no estado de Goiás, em específico. Para alcançar o objetivo proposto abordaremos o histórico e os tipos de investimentos externos utilizados no setor sucroenergético brasileiro e goiano, bem como as consequências desses investimentos para a região de Goiás.

O artigo está dividido em cinco seções: a primeira apresenta uma contextualização teórica acerca dos investimentos estrangeiros nas economias nacionais. A segunda seção versa sobre os tipos de investimento externo e suas formas de entrada na economia de um país. A terceira contextualiza historicamente os avanços do capital internacional no Brasil. A quarta seção trata da internacionalização do capital no setor sucroenergético brasileiro e goiano. A 
quinta e última aborda as consequências desse processo nas áreas econômicas, sociais e ambientais para o estado de Goiás, com enfoque nos impactos para as comunidades e a biodiversidade local.

\section{Contextualizando a participação do capital estrangeiro na economia brasileira}

Empresas e investidores ligados ao capital internacional sempre exerceram influência sobre a economia brasileira, em maiores ou menores graus de acordo com o período histórico, contando geralmente com o estímulo ou ao menos a conivência do Estado. Apesar dessa presença constante, está longe em haver unanimidade entre os teóricos das ciências econômicas, políticas e sociais em relação aos efeitos benéficos ou maléficos dos investimentos estrangeiros na economia nacional.

Os pesquisadores com tendências nacionalistas e os pensadores desenvolvimentistas da Comissão Econômica para a América Latina e o Caribe $\left(\mathrm{CEPAL}^{1}\right)$ viam com reservas os efeitos da presença em grande escala de investimentos externos na economia brasileira. Segundo Prebisch (1968), o lucro exagerado de algumas empresas e a formação de consórcios internacionais que costumam entravar os esforços produtivos nacionais são outros inconvenientes. Para este teórico, o incentivo ao lucro é indispensável para atrair a iniciativa privada estrangeira, porém, essa iniciativa deveria atuar, em contrapartida, como um polo de irradiação de inovação tecnológica em território nacional. A crítica desse autor não estava ligada à presença do capital estrangeiro em si, mas a forma como o Estado lidava com a participação desse capital na economia nacional, sobretudo ao permitir que este capital transferisse para o exterior a maior parte dos lucros auferidos no país e não exigir transferência de tecnologias e inovações técnicas que pudessem aumentar a competitividade da economia nacional.

Para Cardoso e Faletto (2004), autores da Teoria da Dependência, a aproximação com os países ricos e a abertura do mercado interno ao capital proveniente desses países seriam a chave para a superação ou ao menos atenuação do problema da dependência. Isso implica, consequentemente, que a entrada do investimento externo deveria ser estimulada sem restrições ou imposição de contrapartidas aos investidores, uma linha diversa do que propõe a teoria cepalina. Mais crítica é a visão liberal, que defende o estímulo ao capital estrangeiro e a redução do papel do Estado como estratégias para o crescimento econômico, como mostram Vieira e Santos (2012, pp. 355-356): 


\begin{abstract}
A corrente liberal, que tem como destaques Eugênio Gudin e Otávio Gouveia de Bulhões, na década de 1960, priorizava a estabilização da economia, o aumento da produtividade, o estímulo às exportações, a liberdade para o capital estrangeiro e o Estado mínimo como alternativas para o crescimento econômico. [...] Para os economistas liberais, entre eles Gudin (1969), a escassez de poupança interna e o baixo estímulo à entrada de capitais externos provocava o aumento nas taxas de juros internas, reduzindo os investimentos e, consequentemente, o crescimento econômico.
\end{abstract}

O pensamento liberal defendeu, portanto, a completa abertura e mesmo favorecimento ao capital estrangeiro sem quaisquer espécies de restrições ou contrapartidas. Também defendeu a liberdade de ação do mercado, que funcionaria segundo as próprias regras com a mínima interferência estatal possível, a não ser no sentido de promover atrativos e condições propícias ao investimento externo, dentre outras prerrogativas fiscais mais básicas.

Vieira e Santos (2012) apontaram também que o pensamento liberal estava voltado para o crescimento econômico, visando aumento da capacidade produtiva do país, e não para o desenvolvimento econômico e social, que seria o crescimento acompanhado da melhoria do padrão de vida da população e por alterações fundamentais na estrutura econômica e social que possibilitam a distribuição mais igualitária das riquezas produzidas.

As mais recentes concepções sobre modelos de desenvolvimento abordaram perspectivas mais amplas que o aumento da riqueza, como a inclusão social e a redução ou mitigação dos impactos ambientais provocados pela ação humana. Seria o que Sachs (2010, p.33) considerava “desenvolvimento includente". No entanto, tais concepções ainda são tratadas como referência ou ideal de metas a serem perseguidas, do que conceitos efetivamente aplicados e postos em prática pelos governos das diversas nações. Por outro lado, como destacou Pinheiro (2004), o Desenvolvimento Sustentável é um conceito ainda em construção, ao passo que a Teoria do Desenvolvimento Econômico é um pensamento já consolidado.

Apesar da falta de elementos teóricos consolidados em comparação às teorias do crescimento econômico e de consenso sobre a abrangência e outros aspectos do conceito, o desenvolvimento sustentável vem ganhando cada vez mais espaço nos discursos políticos, no meio acadêmico, nas mídias e veículos de comunicação e nos diversos segmentos da sociedade como alternativa para substituição ou gradual superação do tradicional modelo de crescimento econômico, considerado cada vez mais insatisfatório (sobretudo do ponto de vista social e também ambiental) e, em longo prazo, insustentável.

Essa mudança do modelo desenvolvimentista deveria se pautar por novas práticas e estratégias para a condução de processos que possam ser considerados sustentáveis. Para 
Buarque (2002), o planejamento desse modelo alternativo deveria ser concebido como um processo técnico e político que possibilitasse o comprometimento e envolvimento da sociedade na tomada de decisões locais, cuja visão estratégica deveria orientar objetivos de longo e médio prazo.

Para a maioria dos teóricos que trabalham com o conceito de desenvolvimento sustentável, o Estado deve desempenhar um papel mais forte em detrimento da livre iniciativa do mercado, que deve ser alvo de regulamentações e mesmo restrições onde se fizer necessário.

Levando em consideração que o capital internacional é reflexo da transnacionalização do poder econômico, ou seja, a expansão do controle de agentes do mercado (grupos, empresas, sociedades anônimas) além das fronteiras nacionais e da jurisdição dos governos nacionais, a ação coordenadora e regulamentar do Estado deve se estender também sobre ele.

\section{Investimento Direto Estrangeiro (IDE): modalidades de atuação no Brasil}

Com a crescente movimentação de capitais nas cadeias de produção através das fronteiras nacionais pela tendência que Saracini e Paula (2006) denominaram “internacionalização produtiva", registrada notadamente a partir da década de 1960, os economistas, cientistas políticos e demais pesquisadores se viram na contingência de conceituar e classificar o investimento externo e suas formas de participação nas economias nacionais em diversos países.

Como apontam Amal e Seabra (2007), os investimentos estrangeiros ${ }^{2}$ podem ser divididos em: de portfólio, ou de carteira, e investimentos diretos. Os investimentos de portfólio não estão orientados para o controle operacional da empresa receptora do capital externo, enquanto os investimentos diretos visam adquirir um interesse duradouro e maior ou menor grau de influência no processo decisório da empresa. Para estes autores o que define o Investimento Direto Estrangeiro (IDE) é o objetivo do investidor em longo prazo de aquisição e controle de ativos sobre empresa localizada fora de seu país de origem.

Existem diversas formas de entrada do investimento estrangeiro em determinado mercado nacional. Em relação aos modos de entrada no estrangeiro, as empresas podem escolher entre simplesmente exportar (com ou sem um representante de vendas local), licenciar (tecnologia, patentes ou uso da marca) ou fazer investimento estrangeiro direto com propriedade total sobre sua subsidiária no estrangeiro ou numa joint venture com outra 
empresa, seja ela nativa ou não. O novo entrante no mercado também pode optar entre o crescimento orgânico (greenfield) ou a aquisição de empresa que já atue no mercado estrangeiro.

O IDE refere-se à transferência de ativos e de capacidade produtiva através da construção de novas plantas (o chamado investimento tipo greenfield ${ }^{3}$ ) e também através dos processos conhecidos como fusão e aquisição (SARACINI; PAULA, 2006). O investimento greenfield seria mais vantajoso para o país receptor do IDE, já que nesse processo ocorre aumento da capacidade produtiva enquanto nas fusões e aquisições ocorre a incorporação de unidades produtivas já existentes. Por outro lado, as fusões e aquisições são formas bastante recorrentes de entrada do investidor estrangeiro, pois possuem as vantagens de uma estrutura já montada e ativa no mercado.

O processo de liberalização econômica verificado na maior parte do mundo nos anos 1980 constituiu-se em poderoso fator de estímulo para o IDE, que encontrou um cenário bem mais receptivo do que nas décadas de 1960 e 1970 tanto nos meios políticos como acadêmicos (LIMA JÚNIOR, 2005). Durante essas décadas os governantes e intelectuais dos países em desenvolvimento viam com desconfiança o capital estrangeiro e as empresas multinacionais como possíveis fontes de limitação da soberania nacional, de aumento da dependência econômica e de risco para a indústria nacional e o nível de empregos. Bem diverso foi o cenário delineado a partir dos anos 1990, que se caracterizou pelas políticas de atração de IDE em países como o Brasil e pelo reconhecimento nos meios acadêmicos e produções de pesquisa dos benefícios em potencial desse tipo de investimento para os países receptores como a transferência de recursos, tecnologia, na criação de empregos, aumento da competitividade.

Levando em consideração que cada país adota uma política econômica própria, podese inferir que cabe aos governos nacionais definir o que considera investimento estrangeiro e qual será o tratamento dado a este em seus respectivos territórios. Tratando-se, contudo, de um fator bastante relevante no contexto da economia mundial, as instituições financeiras internacionais não podem se escusar de expressar seu posa inserção de capital externo nas economias locais. A recomendação do Fundo Monetário Internacional (FMI) e da Organização para a Cooperação e Desenvolvimento Econômico (OCDE) é que os países considerem como Investimento Direto Estrangeiro apenas as aquisições acima de $10 \%$ do total da empresa, valor estimado por esses órgãos para capacidade de influenciar no processo decisório da mesma (SILVA, 2013). 
Apesar dos esforços de órgãos internacionais como FMI, OCDE, Banco Mundial entre outros no sentido de coletar e disponibilizar informações sobre a movimentação do capital transnacional ou internacional, os dados quantitativos levantados carecem de maior precisão. Estudos feitos por Silva (2013) apontaram que tem sido difícil mensurar corretamente os fluxos e estoques de Investimento Direto Estrangeiro e que os dados oficiais compilados pela Conferência das Nações Unidas para o Comércio e Desenvolvimento (UNCTAD) não correspondem a seus valores reais.

No caso específico do Brasil, o país segue a recomendação do FMI e da OCDE, uma vez que a receita federal considera investimento estrangeiro direto aquele em que o investidor tem mais de $10 \%$ das ações com direito a voto em uma empresa, classificando como “investimento em carteira" os inferiores a este percentual (RECEITA FEDERAL, 2014).Para fins de registro e contabilidade, o Regulamento do Mercado de Câmbio e Capitais Internacionais (RMCCI) do Banco Central determina que devem ser registrados como investimento estrangeiro direto a participação de investidor não residente em capital social de empresas brasileiras e o capital de empresa estrangeira autorizada a operar no Brasil (BANCO CENTRAL, 2014).

O governo brasileiro permite, portanto, a entrada do capital externo sob a forma de Investimento Direto Estrangeiro (IDE) tanto em casos de participação e sociedade com empresas nacionais quanto em empreendimentos próprios de empresas com matrizes e sedes localizadas fora do país impondo como condição o registro nos órgãos governamentais de fiscalização financeira, monetária ou comercial dessas movimentações de capitais, sejam elas realizadas em moeda nacional ou estrangeira. Pode-se considerar essa relativa permissividade como um dos sinais da tendência neoliberal da política econômica brasileira, iniciada na década de 1990 e mantida em suas linhas gerais pelo governo Luís Inácio Lula da Silva (PRATES, 2006).

A Lei $n^{\circ} 4.131$, de 3 de setembro de 1962, e com suas alterações posteriores, é a que regulamenta o tratamento do capital estrangeiro no país. Segundo o Caput dessa lei, considera-se capital estrangeiro (BRASIL, 1962):

[...] os bens, máquinas e equipamentos, entrados no Brasil sem dispêndio inicial de divisas, destinados à produção de bens ou serviços, bem como os recursos financeiros ou monetários, introduzidos no país, para aplicação em atividades econômicas desde que, em ambas as hipóteses, pertençam a pessoas físicas ou jurídicas residentes, domiciliadas ou com sede no exterior. 
Essa Lei definiu também que não haverá discriminação do capital estrangeiro em relação ao capital nacional, salvo as previstas na própria lei, exigindo, no entanto, a obrigação de que seja registrado todo o investimento estrangeiro realizado no país (BRASIL, 1962).

O capital estrangeiro está presente na economia brasileira desde os tempos da colonização, no contexto mercantilista. Prado Jr. (2006) e Furtado (2008) ressaltaram que há indícios abundantes de que o capital proveniente dos Países Baixos (atuais Bélgica e Holanda) foi amplamente empregado não apenas no refinamento e na comercialização do açúcar, mas na própria instalação dos engenhos na região Nordeste do Brasil. Esse exemplo precoce de participação de recursos externos na estrutura econômica da colônia portuguesa reflete a orientação externa dessa estrutura, voltada antes de tudo para o contexto do comércio europeu.

Em meados do século XIX, embora a economia nacional estivesse fortemente atrelada à atividade agroexportadora cafeeira, o Brasil conheceu uma fase de industrialização caracterizada pelos avanços na infraestrutura e pelo desenvolvimento da indústria de base, notavelmente a siderúrgica. Essa fase caracterizou-se pela vinda de capital estrangeiro, que, à época, investia, em sua maior parte, na construção de ferrovias, de portos, transporte urbano (bondes) e outras obras de infraestrutura e serviços de utilidade pública, sendo os britânicos a fonte principal e por vezes mesmo exclusiva do capital externo que entrou no país durante o período oitocentista, seguido muito de longe pela França a partir do terceiro quartel do século (ALMEIDA, 2001).

Já na segunda metade da década de 1950, o capital internacional contribuiu com boa parte dos investimentos que financiaram o notável desenvolvimento econômico e industrial brasileiro daquele período. Essa participação foi bastante estimulada pela Superintendência da Moeda e do Crédito (SUMOC), órgão antecessor do Banco Central, vinculado ao Ministério da Fazenda (Instrução 113). Segundo Gonçalves (1996, p. 9), “[...] entre 1955 e 1960 foi aprovado através do mecanismo da SUMOC U\$ 507 milhões de um total de U\$ 609 milhões em investimentos externos que entraram no país durante aquele período". Isso significa que mais de $90 \%$ do capital estrangeiro que ingressou no Brasil naquele quinquênio foi beneficiado pela Instrução 113 da SUMOC, que funcionou como um atrativo institucional para a entrada do capital estrangeiro nesse período. Facilitava a entrada do investimento externo através da diminuição da burocracia e da instituição de um sistema cambial que oferecia remuneração atraente (CAPUTO, 2007). 
Segundo estudos do IPEA (2010), durante a década de 1950 a maior parte do investimento feito por multinacionais no país estava voltada para os setores automobilístico, farmacêutico e metal-mecânico. Posteriormente, os governos militares (1964-1985) partiam do pressuposto de que os países subdesenvolvidos como era o caso do Brasil sofriam escassez de capital, sendo necessário que esses países atuassem como importadores desse bem, cabendo ao Estado gerar medidas no sentido de atrair e facilitar a entrada de recursos externos na economia nacional.

O quadro intervencionista mudou nos anos 1990 com o afastamento do Estado como agente indutor do desenvolvimento industrial e a liberalização comercial, que se caracterizou inclusive pela maior abertura ao investimento estrangeiro (SUZIGAN; FURTADO, 2006). Essa fase da história econômica brasileira, representada pelos governos Fernando Collor de Mello (1990-92) e Fernando Henrique Cardoso (1994-2002), ficou conhecida por isso como o período neoliberal ${ }^{4}$.

No decorrer da década de 2000, o governo Luís Inácio Lula da Silva deu continuidade a essa política de abertura financeira, através de medidas como a unificação de mercados de câmbio livre e flutuante e a extinção das contas correntes para não-residentes, eliminando limites para que pessoas físicas e jurídicas convertessem reais em dólares e remetessem ao exterior, e também a concessão de estímulos físcais aos investimentos estrangeiros na aquisição da dívida pública, sancionada pela Medida Provisória 281 (PRATES, 2006). Essa Medida Provisória, convertida na Lei 11.312-2006, reduziu a zero as alíquotas do imposto de renda referente aos rendimentos oriundos de títulos públicos pagos, entregues ou remetidos a domiciliados ou residentes no exterior (BRASIL, 2006), beneficiando assim o investidor externo no mercado financeiro nacional.

Nos últimos anos, a participação do capital estrangeiro continuou aumentando. Segundo dados da Sociedade Brasileira de Estudos de Empresas Transnacionais e Globalização Econômica (SOBEET) entre 2009 e 2012 o Brasil subiu do $13^{\circ}$ para o $4^{\circ}$ lugar no ranking dos países que mais receberam investimento estrangeiro. O Censo Anual 2013 do Banco Central contabilizou um valor de US\$737,3 bilhões de investimento estrangeiro declarado em dezembro de 2012, registrando um aumento de aproximadamente $6 \% \mathrm{em}$ relação a dezembro do ano anterior. A tendência é que a participação do capital estrangeiro na economia nacional continue aumentando no longo prazo, embora tenha sido registrada pequena queda no fluxo de IDE de 2012 para 2013 (BANCO CENTRAL, 2014). 
A origem das principais fontes de investidores são Estados Unidos e alguns países da Europa, além do Japão, Canadá e alguns pequenos países caribenhos que se configuram como centros financeiros como Bermudas e Ilhas Cayman (BANCO CENTRAL, 2013). Com relação à distribuição setorial do IED, o Censo aponta que:

\footnotetext{
A estatística de alocação setorial do estoque total do IED foi construída segundo as atividades econômicas informadas pela empresa como as de maior peso em seu faturamento ou lucratividade. Cada empresa ou grupo econômico no Brasil pôde declarar até cinco atividades econômicas [...]. Nenhuma das demais atividades representou mais de $6 \%$ do estoque total. (BANCO CENTRAL, 2013)
}

Esses dados mostram o dinamismo da atuação do capital estrangeiro no país, distribuído em praticamente todos os setores da economia nacional ainda que em parcelas mínimas. Nesse sentido, apesar da predominância nos ramos da indústria de transformação, das atividades financeiras e relacionadas, do extrativismo e da informação e comunicação, o atual cenário se diferencia bastante dos períodos anteriores à década de 1950, nos quais o capital externo concentrava-se em setores específicos, como a produção do açúcar nos tempos coloniais e as obras de infraestrutura e transporte no final do século XIX.

\section{Capital internacional na agropecuária e no setor sucroenergético (Brasil e Goiás)}

A modernização da agropecuária e a integração cada vez maior com os setores da indústria e do comércio, bem como com o consequente aumento da importância da complexidade e do dinamismo das atividades ligadas à exploração da terra, levou ao surgimento do conceito do agronegócio, que define a atual etapa de transformações da agropecuária (BEZERRA, 2009). O agronegócio engloba, portanto, as diversas atividades relacionadas à agropecuária desde as mais básicas etapas produtivas até a cadeia logística de distribuição que chega ao consumidor final.

Durante os anos de 1990, no contexto de expansão e internacionalização da economia mundial e da política de abertura econômica promovida principalmente durante os governos de Fernando Collor (1990-1992) e Fernando Henrique Cardoso (1994-2002), teve início uma fase de rápida internacionalização do agronegócio brasileiro. Benetti (2004) sustentou que durante essa década, aumentou-se consideravelmente a participação do capital estrangeiro na propriedade dos ativos das cadeias agroalimentares, principalmente por meio de fusões e aquisições efetuadas por grupos e conglomerados internacionais em território brasileiro. 
O processo de internacionalização do agronegócio acentuou-se na década de 2000 , com a diversificação de grupos multinacionais que investiram nas diversas áreas do ciclo produtivo do setor agropecuário. Duas das principais tradings ${ }^{5}$ norte americana do ramo alimentício, a Cargill e a Bunge, aumentaram a participação com investimentos na produção de fertilizantes, industrialização de alimentícios animal e inclusive no setor financeiro (CORTE, 2013).

Dentre os mais promissores ramos do agronegócio brasileiro, figura o setor sucroenergético. A cana-de-açúcar, que segundo Prado Jr (2006) e Furtado (2008) foi o primeiro cultivo para exportação em grande escala até entrar em decadência em meados dos séculos XVII e XVIII, volta a alcançar importância cada vez maior no cenário econômico brasileiro a partir da década de 1970. (SHIKIDA; BACHA, 1999).

Ocorreu forte expansão do setor sucroenergético na década de 1980 como resultado do Proálcool. Contudo, o programa entrou em crise com a retomada do uso dos combustíveis fósseis em decorrência da queda dos preços do petróleo, ainda naquela década. De acordo com Scandiffio (2005), a introdução da nova tecnologia que possibilitou a fabricação de motores flexíveis $^{6}$ contribuiu para a recuperação da crise em que o setor sucroalcooleiro esteve durante boa parte dos anos 1990. É nesse contexto que iniciam a ampliação dos investimentos do capital estrangeiro no setor. Segundo Benetti (2009), os franceses foram os primeiros a investir, com a aquisição de uma empresa nacional pelo grupo Louis Dreyfus em 2000, seguidos por vários grupos com matrizes nos Estados Unidos e em diversos países europeus e asiáticos.

Estudos realizados por Pasin e Neves (2001) revelam que entre setembro de 2000 e setembro de 2001, das 11 transações realizadas (fusões e aquisições), 7 contavam com participação de tradings internacionais, representando $63,7 \%$ de capital estrangeiro no montante total. Esses dados indicam a rapidez e a intensidade com que teve início o processo de internacionalização das usinas de açúcar e etanol no início dos anos 2000, embora tenha ocorrido em um período relativamente tardio em relação a outros setores da economia nacional.

Essa tendência de internacionalização do setor sucroalcooleiro continuou ao longo da década, como mostram Borges e Costa (2009). Dados compilados e apresentados por estes autores, coletados da $\mathrm{KPMG}^{7}$, apontaram que no ano de 2007 nada menos que 18 das 25 fusões e aquisições (F\&As) realizadas contaram com participação de capital estrangeiro, sendo que 9 das 11 aquisições integrais foram realizadas com capital estrangeiro. Ainda 
segundo dados de Borges e Costa (2009), o número de grupos, empresas e tradings estrangeiras ou multinacionais atuando no setor chegou a $21 \mathrm{em} \mathrm{2007,} \mathrm{somando} \mathrm{um} \mathrm{total} \mathrm{de}$ 34 operações de fusão e aquisição ou joint venture $e^{8}$ realizadas entre 2000 e 2007.

O rol de empresas e grupos estrangeiros consiste, portanto, em um conjunto heterogêneo de nacionalidades e de ramos de negócio. Verifica-se tradings alimentícias como a Cargill, petrolíferas como a Shell e a British Petroleum(BP), entre outras. Merece destaque como referência de análise para este estudo a atuação do grupo Tereos Internacional, companhia francesa que fabrica açúcar e etanol a partir de cereais, tubérculos e cana-deaçúcar na Europa, na África, na China e no Brasil (TEREOS INTERNACIONAL, 2014).

O grupo ainda não desenvolveu a produção de bioenergia a partir dos derivados da cana na África e na China, porém, existe a possibilidade de que, adquirindo no Brasil o know how e a experiência na fabricação de etanol e na geração de bioeletricidade, expanda suas atividades nesse ramo para suas filiais no exterior, apropriando-se assim de matriz tecnológica nacional. Caso esta possibilidade se confirme, verificar-se-ia uma situação inversa daquela que é preconizada pelos defensores do capital estrangeiro, ou seja, neste caso específíco o capital estrangeiro estaria levando tecnologia daqui para fora ao invés de trazer inovação tecnológica para o país.

O processo de internacionalização das unidades produtoras de biocombustível e bioenergia se encontra em estágio avançado. Percebe-se a participação deinvestimentos diretos estrangeiros em processos de fusão ou aquisição, joint ventures ou implantação de novas unidades com capital internacional.

O estado de Goiás figura como uma das mais promissoras frentes de expansão do setor sucroenergético. Segundo Pietrafesa e Santos (2012), esse processo de expansão foi alavancado pela aplicação das propostas do Plano Nacional de Agroenergia (2006-2011), que autorizou a construção de novas usinas em Goiás e também em São Paulo, Minas Gerais e Mato Grosso do Sul. Castro et al (2010) mostraram que não houve expressivo desenvolvimento do setor em Goiás durante a primeira fase do Proálcool, já que o Estado era alvo dos prolongamentos da fronteira agrícola, com ênfase em grãos (soja, milho e sorgo), algodão, arroz e gado. Somente no final da década de 1990 houve notável expansão do setor de açúcar e álcool no Estado.

O avanço do setor no estado de Goiás está fundamentado nos fatores geográficos por contadas vantagens naturais do bioma cerrado e a relativa disponibilidade de terras para expansão da fronteira agrícola; nas condições do mercado; e em fatores políticos e 
institucionais. A distribuição de usinas na região do cerrado resultou de um aproveitamento das características topográficas ${ }^{9}$, edafoclimáticas ${ }^{10}$ e também de melhorias do solo por atividades anteriores, como grãos e pastagens.

Com relação aos aspectos mercadológicos e institucionais da expansão do setor em Goiás, Silva e Peixinho (2012) ressaltaram que ela resulta da combinação entre condições favoráveis de mercado dos derivados de cana-de-açúcar e ações estatais de incentivo ao setor, principalmente por meio da aplicação de políticas públicas voltadas ao financiamento, à isenção fiscal e à delimitação de áreas consideradas prioritárias para serem ocupadas pelas usinas e pela lavoura canavieira. Tal afirmação é confirmada pelo secretário de Agricultura, Pecuária e Irrigação do Estado de Goiás (GOIÁS AGORA, 2014):

\begin{abstract}
Goiás é um dos estados que mais desenvolveram a cultura da cana-de-açúcar nos últimos anos, especialmente na última década. Isso aconteceu por conta de estímulos recebidos pelas indústrias, pelos produtores e também pelas características que nós temos para a produção dessa cultura: clima, solo fértil e os investimentos feitos pelo Governo do Estado na reconstrução de estradas e na estruturação dos incentivos para a implantação de novas indústrias em Goiás.
\end{abstract}

Paralelamente à expansão de usinas em território goiano, registrou-se a partir da segunda metade da década de 2000, a entrada cada vez maior de investimento estrangeiro tanto na construção de novas usinas quanto na aquisição de unidades já existentes. A participação do capital internacional está ligada ao desenvolvimento do mercado de etanol com os carros flexfuel (SCANDIFFIO, 2005), da bioeletricidade a partir de derivados da cana, da disponibilidade de terras para expansão da fronteira agrícola e das políticas de expansão das fontes renováveis na matriz energética brasileira.

Com a construção do ambiente propício ao investimento internacional no setor sucroenergético, houve o deslocamento de grandes parcelas de IDE de outras culturas para a agroindústria canavieira. Como apontaram Pietrafesa e Pietrafesa (2013, p. 246):

Entre as tradings do agronegócio, que tradicionalmente estavam voltadas à comercialização de grãos, passaram a atuar no setor sucroenergético, está a Cargill(de origem americana), que em 2006 adquiriu 64\% da Companhia Energética do Vale do Sapucaí (CEVASA). Em meados de 2011, a empresa anunciou a constituição de uma joint venture com a Usina São João, que construiu duas unidades em Goiás [...]A empresa americana Archer Daniels Midland (ADM), também atuante no setor de alimentos, adquiriu parte de usinas instaladas no Sul de Goiás e no Triângulo Mineiro. Estratégia adotada pela Sojitz Corporation (Japão), que em 2007 adquiriu $33 \%$ do da ETH (município de Jatai-GO), junto ao grupo brasileiro Odebrecht. 
O processo de apropriação de fatias cada vez maiores da agroindústria canavieira no Brasil e em Goiás tem avançado bastante desde as primeiras iniciativas de grupos estrangeiros visando aquisição de ativos nas usinas, que remonta ao início dos anos 2000. Diante dessa realidade, é importante para o governo e a sociedade brasileira a investigação das consequências do processo de internacionalização no país e mais especificamente no estado em seus aspectos econômicos, sociais e ambientais.

\section{Consequências da internacionalização sucroenergética no Brasil e em Goiás}

O quadro de internacionalização do setor sucroenergético sugere questionamentos da influência desse processo no Brasil e no estado de Goiás. Alguns estudos foram dedicados à análise dos possíveis impactos econômicos, sociais e ambientais da expansão da agroindústria da cana no Brasil em geral e mais especificamente em Goiás. Os estudos, de cunho otimista, em relação às oportunidades da internacionalização, outros apontam os riscos para o meio ambiente (estes como resultados da expansão da lavoura e do crescimento do setor que da internacionalização propriamente dita), da falta de estudos sobre a implicação da aquisição estrangeira de terras em território nacional, em larga escala, dentre outras questões.

Para alguns autores, a entrada do investimento estrangeiro traz benefícios para o desempenho econômico e desenvolvimento tecnológico do setor ao estimular a competitividade e, incorporar ao mesmo, empresas e companhias de perfil dinâmico como as multinacionais, habituadas ao ambiente altamente competitivo do mercado internacional. Meurer e Shikida (2014), por exemplo, afirmam que uma das razões da proeminência atual do estado de Goiás em relação ao quadro nacional do setor sucroenergético é o grande percentual de usinas que investem em inovação e em Pesquisa e Desenvolvimento (P\&D), com parcela representativa do capital internacional.

Centenaro (2012) também sugeriu que a entrada de IDE proporciona avanços ao setor, como investimento em tecnologia e inovação, em modernização e ampliação do setor produtivo. Nessa perspectiva, a presença do investimento estrangeiro seria benéfica por contribuir na modernização e competitividade do setor, figurando como fator que promove a otimização e eficiência e promove as inovações tecnológicas no âmbito sucroenergético. Por outro lado, o Brasil dispõe de matriz tecnológica avançada tanto na produção de etanol combustível quanto no aproveitamento da biomassa da cana para geração de energia. Sendo assim, é de se questionar a relação entre a contribuição das usinas de capital estrangeiro nesse 
desenvolvimento tecnológico e a apropriação de tecnologias desenvolvidas em âmbito nacional por empresas e grupos econômicos internacionais.

Outros estudos foram cautelosos sobre a influência cada vez maior do capital internacional sobre a expansão do setor em si. Dentre as várias preocupações com relação à expansão de área cultivada de cana figura o de segurança alimentar, em posição de destaque: “Com a expansão da agroindústria da cana-de-açúcar no Brasil, um importante tema que tem sido debatido são os possíveis aumentos de preços de alimentos cujos cultivos vêm sendo substituídos pela atividade canavieira" (IPEA, 2010, p. 9)

O investimento estrangeiro pode agravar o problema dos preços dos gêneros alimentícios de duas maneiras: primeiro, ao contribuir com a expansão da lavoura canavieira, limitando assim o espaço para a diversificação de outras culturas; e segundo, pela aquisição de terras por agentes externos, provocando assim aumentos no valor dos imóveis rurais, o que por sua vez impacta no preço dos alimentos.

De fato, uma das consequências da internacionalização do agronegócio em geral, com grande influência do setor sucroenergético em particular, é a estrangeirização da propriedade fundiária e seus efeitos no mercado de terras e na flutuação dos preços (SAUER; LEITE, 2012). Segundo Batista (2010), estudos feitos pelo NAI Commercial Properties registram um aumento de $17 \%$ no preço do hectare de terra de 2009 para 2010 no município goiano de Edeia onde estava localizado o projeto da usina Tropical S/A, parceria entre a petroleira British Petroleum (BP) com o grupo Maeda (posteriormente vendido ao fundo Arion Capital, que terá o nome mudado para $L A P L A C E$ Finanças) e da Santelisa Vale, sob controle do grupo francês Louis Dreyfus Commodities (LDC).

Alvim e Moraes (2013) também salientaram que o investimento estrangeiro tem contribuído para a mudança nas atividades agrícolas, promovendo a agricultura voltada à produção de energia em detrimento da produção de alimentos para consumo doméstico. Além do aumento no custo dos alimentos a pressão da demanda estrangeira pela aquisição de terras pode contribuir para agravar ainda mais situações de tensão e miséria resultantes da concentração fundiária principalmente em regiões de fronteira agrícola. Deve-se considerar que os efeitos da expansão da lavoura de cana-de-açúcar e do aumento dos preços de terras pela demanda estrangeira atingem, particularmente, a parcela mais desfavorecida da população em um país de elevada desigualdade social como o Brasil.

Além de questões alimentares, sobre a qual têm sido desenvolvidos vários estudos nos últimos anos, existe o problema do avanço da cultura da cana sobre regiões de vegetação 
nativa, sobretudo do cerrado, e também as consequências sociais da estrutura de trabalho da agroindústria canavieira.

Com relação aos impactos do processo de expansão da lavoura canavieira em áreas de cerrado, diversos estudos e levantamentos de dados feitos por instituições governamentais e não-governamentais divergem entre si. Segundo Picoli et al (2013, p. 7561):

\begin{abstract}
A conclusão que se chega é que a cana-de-açúcar vem avançando principalmente sobre pastagem e a cultura da soja. Porém, no período houve também desmatamento do cerrado na área estudada e isso pode ter sido parcialmente causado pela expansão da cultura. Com a substituição das áreas de pastagem e de soja é possível que as mesmas se desloquem para outras regiões, o que caracteriza o chamado ILUC (Indirect Land Use Change ${ }^{11}$ ).
\end{abstract}

Outras fontes de pesquisa apontam evidências de que o discurso já amplamente difundido e usualmente bastante aceito em vários ambientes, acadêmicos ou não, de que a expansão da agroindústria canavieira avançou principalmente sobre áreas degradadas de pastagens, ou de cultivos anteriores abandonados, não tem expressado a realidade, uma vez que vem avançando e disputando áreas de soja, milho e sorgo, além de forcarem a abertura de novas áreas de cerrado para as pastagens e as lavouras pressionadas. Com efeito, segundo alguns autores, esse discurso bem acolhido por servir como defesa de certos e específicos interesses em realidade mascara o fato de que as lavouras da cana apresentam risco cada vez maior para as vegetações do cerrado, como se pode verificar em Castro et al (2010):

Ao norte, o avanço deu-se sobre áreas de vegetação nativa, inclusive Áreas
Prioritárias para Conservação (Castro et al., 2007), o que é preocupante do ponto de
vista ambiental, já que essa conversão refere-se a $15 \%$ e $6 \%$ da área ocupada pela
expansão da cana, anteriormente formada por cerrado e mata, respectivamente. De
fato, apenas $12 \%$ da expansão ocorreu em áreas de pecuária, dado que contradiz
fortemente o discurso oficial de que as áreas prioritárias a serem incorporadas
proviriam das pastagens degradadas (Castro et al, 2007; Miziara, 2009; Silva e
Miziara, 2010). Em relação ao eixo de expansão, Silva e Miziara (2010) mostraram
que a cana está entrando em novas áreas do extremo sudoeste, embora no restante
consolide e até potencialize o eixo anterior, o que já era esperado, em razão das
aptidões e da logística existente.

Como visto acima, é possível identificar que não há homogeneidade nas analises e estudos sobre o processo de internacionalização das usinas e a expansão sucroenergética. De modo geral ocorreram alterações no uso do solo, na quantidade de produtos alimentícios colhidos na região do cerrado, no preço as terras desta região, fenômenos que também poderiam ocorrer se as unidades produtivas estivessem controladas pelo capital brasileiro. Será necessária uma atenção no movimento do capital nacional e internacional frente ao setor e, isso só é possível a médio e longo prazo, uma vez que as relações econômicas devem ser 
avaliadas em uma margem histórica maior que as duas primeiras décadas deste século. Parece-nos que uma das questões centrais a serem percebidas e analisadas, com muita atenção, é que riscos poderão surgir no Brasil e no estado de Goiás, em particular, o controle internacional e privado de parte considerável de nossa matriz energética, além do uso e exploração de vastas extensões de terra que o setor sucroenergético necessita. Vários estudos apontaram esses impactos, mais ainda faltam trabalhos dedicados a uma análise mais ampla e aprofundada no sentido de estabelecer uma relação entre custos e benefícios do crescimento do setor e da entrada de IDE no Brasil e em Goiás principalmente para as regiões e comunidades onde ocorrem a presença das lavouras de cana-de-açúcar e suas unidades produtivas.

\section{Considerações Finais}

Vários estudos apontaram esses impactos, mais ainda faltam trabalhos dedicados a uma análise mais ampla e aprofundada no sentido de estabelecer uma relação entre custos e benefícios do crescimento do setor e da entrada de IDE no Brasil e em Goiás principalmente para as regiões e comunidades onde ocorrem a presença das lavouras de cana-de-açúcar e suas unidades produtivas.

O setor sucroenergético teve notável crescimento durante a década de 2000, impulsionado por diversos fatores, com destaque para as novas tecnologias como os motores bicombustíveis, que permitem o uso simultâneo do etanol ou da gasolina, a busca por alternativas renováveis e menos poluentes aos derivados do petróleo e o desenvolvimento tecnológico acumulado por anos de experiência na produção de álcool combustível e no trato da cana-de-açúcar.

Essa expansão veio acompanhada de crescente fluxo de entrada de investimento estrangeiro na agroindústria canavieira, atraído pelas perspectivas favoráveis do momento e também projeções de crescimento a longo prazo na medida em que a tendência de substituição dos fósseis vai se consolidando. As primeiras investidas do capital internacional no setor sucroenergético brasileiro remontam ao início dos anos 2000, quando a primeira companhia estrangeira, a francesa Louis Dreyfus Commodities (LDC) efetuou a aquisição de uma usina no Estado de São Paulo. Em Goiás, tanto a expansão da cana-de-açúcar quanto o ingresso do IDE no setor sucroenergético ocorreu tardiamente em relação a São Paulo, porém, atualmente nota-se avanços cada vez maiores da agroindústria da cana em terras goianas, bem 
como crescente interesse e atuação de conglomerados internacionais como, por exemplo, a

British Petroleum (BP), presente nos municípios goianos de Edeia e Itumbiara.

A internacionalização sucroenergética é, portanto, uma tendência em curso tanto no Brasil como no Estado de Goiás. Resta saber se essa tendência traz benefícios ao país e se pode melhorar não só o desempenho econômico, mas também a eficiência na produção de energia limpa ou, ainda, se atende apenas aos interesses do capital, representados pelos grandes grupos que conduzem a vanguarda do processo.

\section{Notas}

\footnotetext{
${ }^{1}$ A CEPAL, criada em 1948 como uma das cinco comissões econômicas da ONU, é uma organização que reúne vários nomes do pensamento desenvolvimentista latino-americano

${ }^{2}$ São encontradas diferentes denominações para investimento estrangeiro nas diversas fontes; ora denomina-se Investimento Direto Estrangeiro (IDE), ora investimento externo direto ou investimento estrangeiro direto (IED) ou simplesmente investimento estrangeiro ou externo.

${ }^{3} \mathrm{O}$ investimento tipo "greenfield", refere-se a projetos incipientes, ou seja, na implantação de uma unidade ainda não construída, ao contrário dos investimentos tipo "brownfield", nos quais os recursos são investidos em uma estrutura pronta (MOREIRA; ALMEIDA, 2013)

${ }^{4}$ Sobre as políticas de Estado com propostas neoliberais, ver: Anderson (1995)

${ }^{5}$ Trading Companies são empresas especializadas em importação e exportação, realizando a função de intermediários entre produtores e demais canais de distribuição ou consumidores em diferentes países, geralmente concentrando em um ramo ou área do comércio específica (KUNZLER, 2000)

${ }^{6}$ Os chamados motores flex, permitem o uso tanto da gasolina quanto do etanol como combustível nos automóveis

${ }^{7}$ A KPMG é uma rede global de firmas que prestam serviços de auditoria, taxas, serviços contábeis e Consultoria de Gestão e Estratégica, dentre outras áreas relacionadas

8 A expressão "joint venture" se refere a uma união entre duas ou mais empresas visando uma atividade econômica ou empreendimento comum por determinado período de tempo. As empresas que realizam uma joint venture são juridicamente independentes e podem optar por constituir nova empresa ou fazer um consórcio de empresas no processo de criação da joint venture

${ }^{9}$ Topografia é a ciência dedicada à representação no papel dos acidentes geográficos e relevo de determinado local (FERREIRA, 1977).

${ }^{10}$ Edafologia é a ciência que trata da influência dos solos em seres vivos, particularmente plantas, incluindo o uso do solo pelo ser humano com a finalidade de proporcionar o desenvolvimento das plantas (FENILLI, 2014)

${ }^{11}$ Mudança indireta de uso da terra
}

\section{Referências}

ALMEIDA, P R de. 2001.Formação da diplomacia econômica brasileira. São Paulo: Editora Senac.

ALVIM, A M; MORAES S L. Os investimentos estrangeiros diretos no agronegócio brasileiro - 2002-2008. Indicadores Econômicos, FEE, Porto Alegre, v. 40, n. 3, p. 105-120, 2013.

AMAL, M; SEABRA, F. Determinantes do Investimento Direto Externo (IDE) na América Latina: Uma Perspectiva Institucional. Revista EconomiA,Brasília(DF), v.8, n.2, p.231-247, maio/ago 2007. Disponível em: <http://www.anpec.org.br/revista/vol8/vol8n2p231_247.pdf. >Acesso em: 15/02/2014 
ANDERSON, P. Balanço do Neoliberalismo. In SADER, Emir e GENTILI, Pablo (orgs.) Pós-neoliberalismo: as políticas sociais e o Estado democrático. Rio de Janeiro: Paz e Terra, 1995, p. 9-23.

BANCO CENTRAL. Censo de Capitais Estrangeiros no País. Resultados, Anos-base: de 2010 a 2013.2 Disponível em: http://www.bcb.gov.br/Rex/CensoCE/port/resultados_censos.asp?idpai=CENSOCE. Acesso em: $21 / 02 / 2014$

BATISTA, F. Cana mantém aquecido o mercado de terras. Valor Econômico. 02/08/2010. Disponível em: <http://www.valor.com.br/arquivo/839029/cana-mantem-aquecido-mercadode-terras> Acesso em: 15/03/2014

BENETTI, M. D. A internacionalização real do agronegócio brasileiro: 1993-2003. Indicadores Econômicos. FEE, Porto Alegre, v. 32, n. 2, p. 197-222, ago. 2004. Disponível em: $\quad<$ revistas.fee.tche.br/index.php/indicadores/article/viewFile/260/454.>Acesso em: $18 / 05 / 2014$.

. A internacionalização recente da indústria de etanol brasileira. Revista eletrônica da Fundação de Economia e Estatística, Rio Grande do Sul, v. 36, n. 4, 2009. Disponível em: $<$ http://revistas.fee.tche.br/index.php/indicadores/article/view/2220/2620.> Acesso em: $25 / 06 / 2014$

BEZERRA, J. E. Agronegócio e ideologia: contribuições teóricas. Presidente Prudente, REVISTA NERA - ANO 12, No. 14 - JANEIRO/JUNHO DE 2009. Disponível em: http://revista.fct.unesp.br/index.php/nera/article/viewArticle/1384. Acesso em 21/05/2014

BORGES, A. C. G; COSTA V. M. H de M. Fusões e aquisições do setor sucroalcooleiro pós desregulamentação.XXIX Encontro Nacional de Engenharia de Produção.Salvador, Bahia, 06 a 09 de nov. de 2009. Disponível em: $<$ http://www.abepro.org.br/biblioteca/enegep2009_TN_STO_097_657_13658.pdf.> Acesso em: $28 / 07 / 2014$

BRASIL. Lei 11.312-2006. Reduz a zero as alíquotas do imposto de renda e da Contribuição Provisória sobre Movimentação ou Transmissão de Valores e de Créditos e Direitos de Natureza Financeira - CPMF nos casos que especifica; altera a Lei no 9.311, de 24 de outubro de 1996; e dá outras providências.Brasília, DF, 27 de junho de 2006.Disponível em: $<$ http://www.planalto.gov.br/ccivil_03/_Ato2004-2006/2006/Lei/L11312.htm> Acesso em: $21 / 04 / 2014$

. Lei 4.131-1962. Disciplina a aplicação do capital estrangeiro e as remessas de valores para o exterior e dá outras providências. Brasília, DF, 3 de setembro de 1962. Disponível em: <http://www.planalto.gov.br/ccivil_03/leis/L4131.htm> Acesso em: $21 / 04 / 2014$

BUARQUE, S. C. Construindo o Desenvolvimento Local Sustentável: Metodologia de Planejamento. São Paulo. Editora Garamond,2002 
CAPUTO, A. C. Desenvolvimento econômico brasileiro e o investimento direto estrangeiro: uma análise da instrução 113 da Sumoc - 1955/1963. Tese de mestrado. Universidade Federal Fluminense: Rio de Janeiro, 2007.

CARDOSO, F. H; FALETTO, E. Dependência e desenvolvimento na América Latina: ensaio de interpretação sociológico. Rio de Janeiro. Editora Civilização Brasileira, 2004.

CASTRO, S. S; ABDALA, K; SILVA, A. A; BÔRGES, V. M. S. A expansão da cana-deaçúcar no cerrado e no estado de Goiás: elementos para uma análise espacial do processo.Boletim Goiano de Geografia, ISSN 0101-708X, ISSN-e 1984-8501, Vol. 30, № . , 2010 , pp. 171-191. Disponível em:

$<$ http://dialnet.unirioja.es/servlet/articulo?codigo=3712467> Acesso em: 28/07/2014

CENTENARO, M. 2012. Um estudo sobre investimento direto externo no setor sucroenergético do estado de mato grosso do sul. Tese de doutorado. Universidade do Vale do Rio dos Sinos - UNISINOS: São Leopoldo, RS.

CORTE, T. D. O processo de internacionalização do agronegócio brasileiro: os fatores determinantes para sua consolidação, seus desafios e gargalos.Anais Eletrônicos do II Congresso Internacional de História Regional (2013) - ISSN 2318-6208.

FENILLI, T. A. B. Edafologia - Solos florestais e nutrição de espécies florestais. Furb. Disponível em: $<$ http://home.furb.br/tfenilli/> Acesso em: 10/05/2014

FERREIRA, A. B. H. Minidicionário Aurélio. 2 ed. Rio de Janeiro: Editora Nova Fronteira, $1977.536 \mathrm{p}$.

FURTADO, C. Formação econômica do Brasil.São Paulo: Companhia das letras, 2008.

GOIÁS AGORA. Goiás é o segundo maior produtor de cana-de-açúcar do País. Entrevista: 08/05/2014. Disponível em: http://www.goiasagora.go.gov.br/goias-e-o-segundo-maiorprodutor-de-cana-de-acucar-do-pais/. Acesso em: 18/05/2014

GONÇALVES, R. Globalização produtiva, investimento direto e empresas transnacionais do Brasil: uma perspectiva histórica. Reunião da Associação Brasileira de História Econômica, dez. $1996 . \quad$ Disponível em: $<$ http://www.reggen.org.br/midia/documentos/globaprodutivaivesextdireto.pdf. $>$ Acesso em: $24 / 02 / 2014$

IPEA. Instituto de Política Econômica Aplicada. O Brasil em 4 décadas. 2010. Disponível em: $\quad<$ http://repositorio.ipea.gov.br/bitstream/11058/1663/1/TD_1500.pdf. >Acesso em: $22 / 04 / 2014$

KUNZLER, J. P. Trading companies: análise do perfil, estratégias e tendências das empresas brasileira. Dissertação de mestrado. UFSC, Florianópolis, 2000. 
LIMA JÚNIOR, A J M. Determinantes do Investimento Direto Estrangeiro no Brasil. Centro de Desenvolvimento e Planejamento Regional Faculdade de Ciências Econômicas - UFMG: Belo Horizonte, 2005.

MEURER A. P. E., SHIKIDA, P. F. A. Análise da Agroindústria Canavieira nos Estados do Centro-Oeste do Brasil a partir da Matriz de Capacidades Tecnológicas. Curitiba: LedZe editora, 2014

MOREIRA, C A L; ALMEIDA, A T. A dinâmica recente do Investimento Direto Estrangeiro (IDE) no Brasil e impactos sobre a conta de transações correntes. Indicadores Econômicos, FEE, Porto Alegre, v. 41, n. 1, p. 9-22, 2013.

PICOLI, M C A; DUFT, D; LEAL M R L V; WALTER A. Avanço do setor sucroalcooleiro na mesorregião do Sul Goiano - GO. Anais XVI Simpósio Brasileiro de Sensoriamento Remoto - SBSR, Foz do Iguaçu, PR, Brasil, 13 a 18 de abril de 2013, INPE. Disponível em: $<$ http://www.dsr.inpe.br/sbsr2013/files/p0457.pdf. > Acesso em: 20/06/2014.

PIETRAFESA, J. P; PIETRAFESA, P. A. Capital internacional e novas fronteiras na produção de bioenergia: Estudo de caso de questões sócio ambientais. In: Fronteira Cerrado - Sociedade e Natureza no Oeste do Brasil. SILVA, S D e; PIETRAFESA J P; FRANCO J L A; DRUMMOND J A; TAVARES G G (orgs). Editora da PUC Goiás: Goiânia, 2013.

PINHEIRO, D. R. C. O Desenvolvimento Sustentável (DS): indicadores de sustentabilidade. Rev. Humanidades, Fortaleza, v. 19, n. 2, p. 92-99, jul./dez. 2004.

PRADO JÚNIOR,C. Formação do Brasil contemporâneo. São Paulo: Brasiliense, 2006.

PRATES, D M. 2006. A inserção externa da economia brasileira no governo Lula. In: A supremacia dos mercados e a política econômica do governo Lula. CARNEIRO, R. (org.). São Paulo: Unesp.

PREBISCH, R. Dinâmica do Desenvolvimento latino-americano. Rio de Janeiro: Ed. Fundo de Cultura, 1968.

RECEITA FEDERAL. 1 - O Investimento Direto Estrangeiro (IDE). Disponível em: $<$ http://www.receita.fazenda.gov.br/aduana/IDE/IDEBrasilEmirados/ide.htm> Acesso em: $18 / 03 / 2014$

REIS, J C. As identidades do Brasil: De Varnhagem a FHC. Rio de Janeiro: FGV, 2007.

SACHS, I. Barricadas de ontem, campos de futuro. 2010. Estudos Avançados, 24 (68).

SARACINI, T; PAULA, $\mathrm{N}$ de. Empresas transnacionais e investimento direto estrangeiro: um survey das principais abordagens. Disponível em: $<$ http://www.economiaetecnologia.ufpr.br/textos_discussao/texto_para_discussao_ano_2006_ texto_21.pdf $>$ Acesso em: 17/03/2014 
SARTI, F; LAPLANE, M F. O Investimento Direto Estrangeiro e a internacionalização da economia brasileira nos anos 1990. Economia e Sociedade, Campinas, v. 11, n. 1 (18), p. 63 94, jan. /jun. 2002.

SAUER, S; LEITE, S. Expansão agrícola, preços e apropriação de terra por estrangeiros no Brasil. RESR. Piracicaba - SP, Vol. 50, N 3, p. 503-524, Jul/Set - 2012.

SCANDIFFIO, M. I. G. (2005). Análise Prospectiva do Álcool Combustível no BrasilCenários 2004-2024. Tese de doutorado, Universidade Estadual de Campinas, 2005. 182 pp.

SHIKIDA, P. F. A. e BACHA, C. J. C. Evolução da Agroindústria Canavieira Brasileira de 1975 a 1995. Rio de Janeiro: FGV, 1999. Disponível em:

$<$ http://bibliotecadigital.fgv.br/ojs/index.php/rbe/article/viewFile/746/1740. > Acesso em: $22 / 05 / 2014$

SILVA, S. T. 2013. Padrão de inserção do Brasil nas cadeias globais de valor: uma análise do Investimento Direto Estrangeiro no país no período de 2003-2012. In: Boletim de Economia e Política Internacional, n.15, IPEA.

SILVA, W. F. e PEIXINHO D. M. A expansão do setor sucroenergético em Goiás: a contribuição das políticas públicas. Campo - Território: Revista de Geografia Agrária, v. 7, n. 13. 2012. Disponível em:

$<$ http://www.seer.ufu.br/index.php/campoterritorio/article/view/13766/8216. > Acesso em: $20 / 07 / 2014$

TEREOS INTERNACIONAL. Disponível em:

$<\mathrm{http}: / / \mathrm{www}$.tereosinternacional.com.br/show.aspx idCanal $=\mathrm{oIh} / 7 \mathrm{VCdBSlCFWJiB5m6PA}=$ $=$. $>$ Acesso em: $21 / 04 / 2014$

VIEIRA, E. T; SANTOS, M. J dos. Desenvolvimento econômico regional - uma revisão histórica e teórica. Revista Brasileira de Gestão e Desenvolvimento Regional, v. 8, n. 2, p. 344-369, mai-ago/2012, Taubaté, SP. Disponível em:

$<$ http://rbgdr.net/revista/index.php/rbgdr/article/viewFile/679/296. >Acesso em: 18/02/2014

Recebido em 10/08/2015.

Aceito para publicação em 27/05/2016. 